\title{
Financial burden of allergen free food preparation in the catering business
}

\author{
A.R. Hoogeveen ${ }^{1,2 \#}$, H.J. van der Fels-Klerx ${ }^{1,2 \#}$, A. Bonanno ${ }^{3}$ and M.G.E.G. Bremer ${ }^{1}$ \\ ${ }^{1}$ RIKILT Wageningen UR (Wageningen University and Research Centre), P.O. Box 230, 6700 AE Wageningen, the \\ Netherlands; ${ }^{2}$ Business Economics Group, Wageningen University, P.O. Box 8130, 6700 EW Wageningen, the Netherlands; \\ ${ }^{3}$ Department of Agricultural and Resource Economics, Colorado State University, Clark B327, Fort Collins, CO 80524, \\ USA; ine.vanderfels@wur.nl; " these authors have contributed equally
}

Received: 20 January 2015 / Accepted: 31 August 2015

(c) 2015 Wageningen Academic Publishers

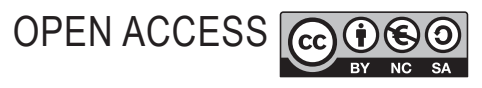

RESEARCH ARTICLE

\begin{abstract}
This study aimed to quantify costs and benefits of allergen free food (food not containing ingredients that fall under the European labelling regime) production at a catering business under two scenarios. In scenario 1 the caterer provides information to the consumer regarding the presence of allergens in the meals served, uses allergen free ingredients in preparation of allergen free meals, but does not avoid cross contamination during food preparation. Scenario 2 expands upon scenario 1 as to also include the prevention of cross contamination during preparation of allergen free foods. A stochastic partial budgeting analysis was performed to simulate the costs and benefits in both scenarios, relative to the current situation of providing neither information regarding the presence of allergens nor serving allergen free meals. Costs values were based upon the adaptations necessary to comply with the two scenarios for an on premise catering location. Fixed and variable cost items were identified via literature review, critical inspection of the catering establishment, and expert opinion. Benefit items were identified and quantified via a questionnaire about willingness to pay and willingness to buy at a catering location, according to each scenario. Given the price increase of meals in accordance to the estimated willingness to pay, and using mean values of the distributions of the costs and benefit items, an investment payback time of 8.1 and 7.7 months was estimated for scenarios 1 and 2, respectively. However, with median values of the distributions, both scenarios were not profitable, since monthly net profits were estimated at $€-413$ and $€-636$ for scenarios 1 and 2 , respectively. If additional costs are not passed on to the consumer, no scenario is profitable. Catering companies can use the methodology and results in their decision making process on serving allergen free foods.
\end{abstract}

Keywords: food allergens, partial budgeting analysis, willingness to pay

\section{Introduction}

The ingestion of even the smallest quantities of allergens with food consumption can have very serious health consequences for food allergic individuals (Watson, 2013). Moreover, the prevalence and severity of food allergies seems to be rising over the years (Hadley, 2006; O'Neil et $a l ., 2011)$. In the USA, for instance, the rate of self-reported allergy to peanuts doubled among children from 1997 to 2002 (Sicherer et al., 2003). In Europe, the lifetime selfreported prevalence of allergy to common foods in Europe ranges from 0.1 to $6.0 \%$ (Gupta et al., 2007; Nwaru et al., 2014). Food allergic persons experience on average two reactions per year, with $30 \%$ of all reactions being severe
(Versluis, 2012). The lethality rate amongst persons with severe food allergic reactions is reported to be $1 \%$ (Flabbee et al., 2008).

Since the avoidance of foods containing allergens is the only way to cope with food allergies, food allergic persons are heavily dependent on the provision of (correct) information about the ingredients contained in the food they consume (Jackson et al., 2008). Food industry managers agree that providing correct information about the presence of food allergens to consumers is highly important (Batt and Noonan, 2009). However, the entire food industry, including catering businesses, may have limited knowledge and ability to provide correct food allergen information (Ahuja and 
Sicherer, 2007; Bailey et al., 2011; Kumar and Budin, 2006; Pratten and Towers, 2003). When food allergen information is not correctly provided on the food label, it will lead to product recalls which are necessary because exposure to the product can cause serious adverse human health consequences or even death (Gendel and Zhu, 2013). In fact, most recalls (34\%) in food industry are due to undeclared allergens, resulting into major costs for food companies (Taylor et al., 2004). Incorrect information on the presence of food allergens in the food product, or no information at all, could also lead to unintentional intake of allergens and impaired health for food allergic consumers. This was acknowledged by the European Commission, establishing Regulation (EU) No. 1169/2011 on the provision of food information to consumers, which was published in November 2011 (EC, 2011). This Regulation obligates the European food industry to provide information on the presence of the fourteen main allergens in food items, for all foods that are produced at the $13^{\text {th }}$ of December 2014 and onwards. Except for gluten, no legal limits exist for the main allergens, and decisions on labelling are based on risk assessment. For gluten, maximum levels are in place, being $20 \mathrm{mg} / \mathrm{kg}$ for the label 'gluten free', as defined in Commission Regulation (EC) No. 41/2009 (EC, 2009). For food items that are packed, information on the presence of allergens must be provided on the food labels. This was already compulsory given to earlier EC Regulations (Directive 2000/13/EC, amended by Directive 2003/89/EC, Directive 2006/142/EC and Directive 2007/68/EC). For non-packed foods, information on food allergens should be presented to the consumer by the food providers. This implies that these providers of unpacked foods, such as catering businesses and restaurants, must have information about the possible presence of the regulated allergens in the unpackaged foods readily available and easily accessible to consumers. This Regulation (EU) No. 1169/2011 prescribes each member state of the European Union to make interpretations on the means by which information on allergens in unpacked food should be made available to consumers (Food Safety Authority Ireland, 2012; KTBA People in Food, 2013).

Although Regulation No. 1169/2011 does not mandate the providers of unpacked food to serve allergen free food and/or to avoid cross-contamination during food preparation (Voedingscentrum, 2013), it may result in food businesses (re-)considering their strategy on serving allergen free foods. In this case, an socio-economic impact analyses is relevant (Poms and Astley, 2011). Complying with the Regulation will lead to additional costs, but may also result into higher returns, in particular when (on top of complying with this regulation) also allergen free food is served. In fact, out-of-home eating establishments may benefit from the ability to perceive higher prices or to attract additional customers thanks to reaching a bigger market (Ajala et al., 2010; Kronenberg, 2012; Leitch et al., 2005). To date, no scientific information is available on the financial burden of serving allergen free food by out-of-home eating establishments such as catering businesses.

The aim of the current study was to estimate the costs and benefits of serving allergen free food and providing information about the presence of allergens in food by an on premise catering business. The focus of the study was on a specific case study, i.e. an on premise catering business company in the Netherlands that operates at the location/ site of the customer (e.g. a specific institute or company), using the customer's equipment to assemble and prepare meals (Hertzman and Barrash, 2007).

\section{Materials and methods}

\section{Partial budgeting}

We adopted a partial budgeting approach to identify and quantify the advantages (reduced costs and added benefits) and disadvantages (added costs and reduced benefits) from allergen free food preparation. Allergen free food, in this study, was defined as food not containing ingredients that fall under the European labelling regime. Two different scenarios were considered: (1) preparation of allergen free foods, without taking measures to avoid cross contamination, and providing information on the presence of allergens in food; and (2) scenario 1 plus implementing a scheme to prevent cross contamination of allergens during food preparation. Costs and benefits were calculated for a specific location of the on premise catering business company in the Netherlands, hereafter called 'study location', considering lunch meals. Costs and benefits were calculated for each of these two scenarios, relative to the baseline scenario of absence of both allergen free food preparation and information on the (possible) presence of allergens in food products (representing the current situation).

Cost items were based on the necessary adjustments that must be made in the specific catering business for each scenario, and were referred to a month of operation. Monthly costs items were classified either as variable (dependent on the production volume, in this case number of meals) or fixed (independent on production volume). Given the short time span of the study, inflation was not considered. Considered benefits for the catering business included the increased potential of the consumers' willingness to purchase meals at the catering business locations (willingness to buy, hereinafter WTB) if allergen free food was sold and the extra price they would be willing to pay for it (willingness to pay, hereinafter WTP). Input data for benefit items were obtained via a questionnaire administered to potential customers of the specific catering company used as case study, since, to the best of our knowledge, there is currently no scientific literature estimating the WTB and WTP for allergen free food. It 
was assumed that the following items did not change in the two simulated scenarios: quality of the meals, labour wages, type of insurance, and insurance costs. Insurance costs did not change, since all catering businesses in the Netherlands have a food safety insurance, and allergens are covered in the current insurance. Furthermore, production costs were considered not to change with production volume, since the increase in number of meals sold when allergen free food is served was considered to be small.

Simulated profits in the two scenarios were calculated by subtracting total monthly costs from total monthly benefits. The payback period (i.e. the number of time periods necessary for a scenario to become profitable, after fixed costs have been recovered) was calculated assuming fixed costs only occurred once when the process of adjustment to scenario 1 or 2 began. The payback period was calculated dividing fixed costs by average monthly profit.

\section{Input data}

Cost items under the two scenarios were identified by: (1) a literature review on critical control points for allergen free food production, preparation and serving; (2) critical inspections at the study location (including swab tests to detect the presence of two regulated allergens, see below) to identify critical control points; and (3) individual personal interviews with some key experts. Key experts were selected based upon their knowledge about the costs and benefits within the specific catering company used for this case study. Hence, the general quality manager of the catering company and the manager of the study location in which the study was performed, were considered the key experts. The experts were interviewed separately to avoid possible influence and interaction between these two persons. Both the literature review and the critical inspections at the study location were used to identify the critical control points for allergen free production, needed to identify the measure that should be taken. Literature review, including primary data collection, and expert data were used to obtain input on the measures and related prices/costs. Sources used for each costs item are provided in the Supplementary Table S1-S3. All input data on prices and costs reflected current prices, and were collected in the period between September 2013 and March 2014.

\section{Critical control point inspection}

Swab tests were performed to identify the possible presence of peanut and gluten (by cross contamination) at critical control points in the food preparation (kitchen) and serving areas of the study location. These two allergens were selected - from the 14 regulated allergens - since they have a high impact on both the food industry and consumers. Gluten is abundantly present in food products and ingredients, because of its beneficial technological characteristics (e.g. elasticity) and low price (Day et al., 2006). Peanut is one of the allergens causing the most severe reactions in allergic individuals (Remington et al., 2013). Critical control points for these two allergens were considered representative for the other 12 main allergens.

Two series of measurements were performed at twenty different potential critical control points during food preparation and serving at the particular location of the catering company. The first series took place before providing specific instructions for prevention of cross contamination of peanut and gluten to the staff preparing and serving the food; the second series, after the instructions had been provided. The first series of measurements was performed on a regular production day after cleaning when peanut sauce and a soup containing gluten were prepared before. One week later, instructions to prevent cross contamination of peanut and gluten were given to the employees. Then, they prepared the same peanut sauce and soup as on the regular production days (the week before), but taking into account the additional instructions. Then, the second series of measurements was performed in the same way as on the regular production day. Swabs were taken before and after providing instructions to investigate the effects of providing extra instructions for cleaning. RIDA ${ }^{\oplus}$ Quick Gliadin for gluten, and Lateral Flow Peanut for peanut, were used, according to manufacturers' instructions (RIDA ${ }^{\oplus}$ Quick Gliadin (R7003; R-Biopharm RG, Darmstadt, Germany), Lateral Flow Peanut (BL606-25; Chakmartin International Ltd., Bangkok, Thailand), and swabbing kit (BS800-25; R-Biopharm RG).

\section{Consumers questionnaire}

The additional revenue items were determined with a survey consisting of 24 questions, and collecting mainly five types of information:

- the demographics of the respondents (income, sex, education, age, profession, and household size);

- perceived importance of food attributes (price, taste, nutrition value, available allergen information);

- whether the respondents and/or their relatives, siblings, and/or colleagues had experienced food adverse reactions in the past;

- average expenditure for a lunch meal at an out-of-home eating establishment;

- the WTP, expressed in percentage relative to the average amount of euros spent for a lunch meal at an out-ofhome eating establishment (when unknown, respondents were asked to assume $\mathrm{a} € 5$ costs for the meal), and WTB, expressed in extra meals bought per month, for each of the two scenarios.

The questionnaire (available upon request) was sent in the beginning of 2014 through esurv.org, an on-line platform, to three different populations. These included, at the 
moment of sending out the questionnaire, all 898 MSc Food Science students of Wageningen University, all 200 employees of a research institute on food safety, and all 280 employees of the headquarter of the catering business. The first two populations can visit the study location (i.e. the location of the considered on premise catering business company), or other locations (canteen, restaurants, etc.). The third population can visit the in-house canteen of the headquarter of the catering business company, where the food was prepared by the same catering business as at the study location; $82 \%$ of this population actually purchase and consume their lunch in the company canteen every day. The first two populations received the English version of the questionnaire, whereas the Dutch version was sent to the employees of the catering business in order to avoid linguistic misunderstandings.

The questionnaire for the student and research organisation populations (first two populations) included questions about the WTB and WTP for scenario 1. Data obtained from these two populations were used to identify the benefit items. The questionnaire for the catering business employees (third population) only included questions on the WTP for the two scenarios. The WTB questions were not relevant for these respondents since the far majority of this population was eating at the company canteen already every day. WTP data collected for scenario 2 from the catering business employee population were used to extrapolate the WTP for the same scenario for the student and the research organisation populations. This was done multiplying the WTP results for scenario 1 from the first two populations (student and research organisation population) by the relative WTP difference between the two scenarios for the catering business employees population.

\section{Simulation analysis}

Data analyses were carried out by performing a Monte Carlo simulation using @Risk 6.1 from Palisade DecisionTools Suite (Palisade Cooperation, Ithaca, NY, USA), with two thousands random draws to simulate stochasticity of the nondeterministic items. Variables which are expected to show relative large natural variation were made stochastic, whereas others were considered deterministic. For the stochastic variables, we used triangular distributions whose minimum, maximum, and most likely values were defined based upon values derived from literature, the interview answers of the two experts, and cost prices for the specific products. The distribution of the benefit items was fitted using the results from the questionnaire on WTB and WTP. The best-fitting distribution was chosen comparing the Akaike information criteria values obtained for different empirical distributions fitting the data. The fitted distributions were truncated at their $95^{\text {th }}$ percentile value to prevent from sampling extremely large values at the positive tail of the distribution during the Monte-Carlo simulation.

\section{Results}

\section{Values for input data}

Input data for the costs and benefit items, as determined by literature, critical control points inspection, interview results, and questionnaire results, are shown in Supplementary Table S1. Values are deterministic unless the distributions of the values are indicated.

\section{Benefit items}

The response rates of the questionnaires were $15 \%$ for the student population (132 out of 898), 21\% for the food safety research institute population (42 out of 200), and $46 \%$ for the catering business population (129 out of 280). The average expenditure for a lunch meal at an out of home eating location was $€ 4$.16. Table 1 presents the results for the benefit items.

Results of the questionnaire showed that $30 \%$ of both the population of students and employees of a food safety research institute showed a positive WTP for allergen free meals and information on presence of allergens (scenario 1). On average, these respondents were willing to pay $4.2 \%$ extra per meal $(€ 0.17)$. If the food business in analysis was able to increase prices to match this additional WTP, the higher WTP will result into extra revenues of $€ 543$ per month. The best fitted distributions for the WTP for scenario 1 was an extreme-value (Gumbel) distribution.

For the catering business population, the extra WTPs for scenario 1 and 2 were 1.9 and $3.1 \%$, respectively, the latter being 1.63 times the former. Therefore, to estimate the WTP for the student and the research organisation populations in scenario 2, the estimated WTP for scenario 1 was multiplied by 1.63 .

$16 \%$ of the student and research organisation populations (29/176 respondents) indicated to be willing to buy food in the particular study location providing information on food allergens, resulting in circa 122 extra meals sold per month. Based on the assumption of 150 customers per day, the survey results indicated that 105 extra meals will be sold monthly. Given an average costs for a meal of $€$ 4.16 and an estimated profit margin for the on premise catering business of $25 \%$, this leads to extra profit of $€ 109$ per month. The distribution for the WTB for scenario 1 showing the best fit was Pareto.

\section{Cost items}

The two experts indicated the fixed items to be deterministic, except for 'Update information about allergens in meals based on action levels'. All variable costs were considered stochastic and their distributions were assumed 
Table 1. Input values for the benefit items for each of the two scenarios considered.

\begin{tabular}{|c|c|c|c|c|c|c|c|}
\hline \multirow[t]{2}{*}{ Benefit item } & \multirow[t]{2}{*}{ Input $^{1}$} & \multicolumn{2}{|c|}{ Benefits scenario 1} & \multicolumn{2}{|c|}{ Benefits scenario 2} & \multirow[t]{2}{*}{ Minimum } & \multirow[t]{2}{*}{ Maximum } \\
\hline & & mean & median & mean & median & & \\
\hline \multirow[t]{4}{*}{ Extra benefits ${ }^{2}$} & WTP for scenario 1 & $€ 491$ & $€ 0$ & & & $€ 0$ & $€ 3,966$ \\
\hline & WTB for scenario 2 & & & $€ 53$ & $€ 0$ & $€ 0$ & $€ 3,001$ \\
\hline & WTP for scenario 1 & $€ 800$ & $€ 0$ & & & $€ 0$ & $€ 6,192$ \\
\hline & WTB for scenario 2 & & & $€ 53$ & $€ 0$ & $€ 0$ & $€ 3,001$ \\
\hline \multirow[t]{5}{*}{ Reduced costs } & Reduced risk of claim & & & $€ 5$ & $€ 0$ & $€ 0$ & $€ 625$ \\
\hline & Benefit without price increase scenario 1 & $€ 53$ & $€ 0$ & & & $€ 0$ & $€ 3,215$ \\
\hline & Benefit without price increase scenario 2 & & & $€ 58$ & $€ 0$ & $€ 0$ & $€ 3,215$ \\
\hline & Benefit with price increase scenario 1 & $€ 544$ & $€ 0$ & & & $€ 0$ & $€ 5,972$ \\
\hline & Benefit with price increase scenario 2 & & & $€ 858$ & $€ 0$ & $€ 0$ & $€ 7,844$ \\
\hline
\end{tabular}

to be triangular (that is, with a minimum, maximum and most likely value), except for 'risk of getting a claim'. This cost item was considered stochastic, as the risk of getting a claim can be reduced by avoiding cross contamination of allergens during food preparation, and was assigned an exponential distribution.

Results of the swab tests before and after the employees received instructions to prevent cross-contamination in the kitchen and serving areas of the study location indicated training resulted in a reduction of allergen contamination. In the first series, $74 \%$ of the investigated critical control points tested positive for gluten (i.e. levels above the detection limit of the swab test). In the second series (after the instructions) $35 \%$ of the investigated points tested positive. Based on these results, in combination with expert opinion, it was assumed that cross-contamination in scenario 1 is twice as large as in scenario 2, as is the risk (and related costs) of a claim.

\section{Model results}

The total fixed costs were estimated at $€ 2,766$ per year for scenario 1 , and $€ 3,976$ per year for scenario 2 . Total variable costs (assuming 150 meals served monthly) were estimated at $€ 206$ for scenario 1 and $€ 342$ for scenario 2 (Supplementary Table S2 and S3).

Mean and median values of the profits distribution for scenarios 1 and 2 are presented in Table 2. As can be seen from this table, the mean is positive, but the median (50 ${ }^{\text {th }}$ percentile) is negative. Moreover, when the price of the meals does not increase to match the higher WTP

Table 2. Total estimated costs and benefits per month, for each of the two scenarios considered.

\begin{tabular}{|c|c|c|c|c|}
\hline Description & Mean & Median & Minimum & Maximum \\
\hline \multicolumn{5}{|l|}{ Costs } \\
\hline Scenario 1 & $€ 437$ & $€ 436$ & $€ 370$ & $€ 1,543$ \\
\hline Scenario 2 & $€ 673$ & $€ 677$ & $€ 580$ & $€ 1,964$ \\
\hline \multicolumn{5}{|l|}{ Benefits } \\
\hline Scenario 1 & $€ 544$ & $€ 0$ & $€ 0$ & $€ 5,972$ \\
\hline Scenario 2 & $€ 858$ & $€ 0$ & $€ 0$ & $€ 7,844$ \\
\hline \multicolumn{5}{|c|}{ Benefits minus costs, with price increase } \\
\hline Scenario 1 & $€ 122$ & $€-413$ & $€-1,529$ & $€ 4,025$ \\
\hline Scenario 2 & $€ 210$ & $€-636$ & $€-1,262$ & $€ 5,775$ \\
\hline \multicolumn{5}{|c|}{ Benefits minus costs, no price increase } \\
\hline Scenario 1 & $€-396$ & $€-431$ & $€-1,557$ & $€ 2,337$ \\
\hline Scenario 2 & $€-634$ & $€-670$ & $€-1,258$ & $€ 2,095$ \\
\hline
\end{tabular}


calculated from the survey, no scenario appears profitable, as both mean and median values of profits are negative.

For scenario 1 , the average total fixed costs were estimated at $€ 2,765$, assuming the on premise catering business is able to charge a higher price to match the estimated additional WTP. Average variable profits (benefits minus variable costs) were estimated at $€ 342$, resulting into a payback period of 8.1 months. For scenario 2, the average total fixed costs were estimated at $€ 3,976$, and variable profits (if higher prices are charged) at $€ 516$, thus resulting into a payback period of 7.7 months. Figure 1 shows the graph of the payback period in both scenarios.

The median of total profits are negative for both scenarios ( $€-413$ and $€-670$, respectively). According to our simulated profit distribution, starting to serve allergen free meals and providing information on allergen presence in served meals will, for the current case study, be economically unfeasible with a probability of $65 \%$.

\section{Discussion and conclusions}

This study assessed the profitability of preparing and serving allergen free food and providing information regarding the presence of allergens in unpacked food at an on premise catering business location. It is the first study that estimated costs and benefits for allergen free production at an out of home eating place. We focused on a particular case study (and particular study location) for which reliable input data was available, but the approach taken can be expanded and applied to other businesses.

WTB and WTP values were estimated based on a questionnaire conducted among potential consumer groups of the catering business. These potential consumer groups represented two specific populations, both being professionally related to food safety and food production. They might thus have a high awareness of food safety and allergens in food, and might have indicated a higher WTB and/or WTP than the average consumer. One of the groups included students who may have less to spend than the general population. Results on the two benefit items might therefore not be representative for the general Dutch population. In addition, questionnaire results might not always give a good presentation of the real life purchase behaviour (Breidert et al., 2006; Johannesson, 1997; Neill et al., 1994). In spite of this potential limitation, this method was used for its cost effectiveness, since a high number of respondents could be reached with relatively limited costs. Furthermore, it allowed to obtain background information on the respondent, such as demographics, which can be used in future research to explain, and possibly predict, WTB and WTP (Breidert et al., 2006). A questionnaire was chosen over using real market data, since: (1) potentially new consumers (currently not visiting the study location)

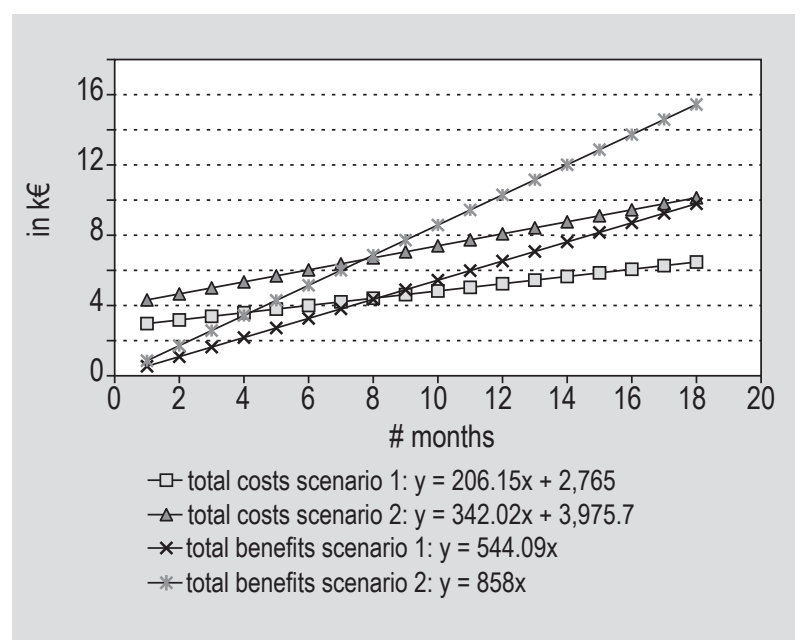

Figure 1. Total costs, total benefits and payback period for each of the two scenarios.

could be included; and (2) no actual market exists for products sold by catering business with the provision of allergen information.

$70 \%$ of the respondents indicated not to be willing to pay anything extra for food with additional information on allergens and where cross contamination was also prevented. This implies that, increasing the price per meal based on the estimated WTP may result in a reduction in the number of customers, and lower revenues. At the same time, if the price of the meals were kept constant, the catering business may benefit from consumers' additional WTB, but the additional revenues would not be enough to cover additional costs, leading to negative profits in both scenarios. It should be noted that it is possible that when more meals are sold the average cost price per meal will decrease because of economies of scale (Trogdon et al., 2013). However, in this study, the cost price was kept constant as there was no indication from the two experts of a likely cost reduction. Another point that should be considered is that, in our surveys, respondents with adverse reaction to shell fish and lactose/milk indicated a higher WTB for meals with allergen information (data not shown and available upon request). This may indicate that individuals with allergies or with food adverse reactions currently do not eat often (or not at all) out of home. As a result, if catering businesses provided more information on presence of allergens and/or served allergen free meals, they could reach an additional group of consumers.

In fact, while this study assessed only benefits for the catering business company, there may be additional benefits for society from the provision of information about presence of allergens, or from the availability of allergen free food. For example, allergic individuals may experience a better quality of life since they may increase the level of out-ofhome consumed meals, feel more sociable, and be able to 
consume a wider variety of food. Furthermore, individuals and society will experience less costs because of the avoided negative health aspects due to unintentional allergic persons exposure to allergens (Van Putten et al., 2010).

A limitation of this study is the estimation of WTP for scenario 2, which assumes the same relative difference in WTP for the two scenarios for different population of respondents. This assumption, needed because of data limitation, may not necessarily hold because of the differences in demographics of the two populations. Moreover, it was assumed that the estimated WTB in scenario 1 could also apply to scenario 2 .

This study and its results provide insights on how catering businesses can cope with allergen free food production and provision of information on the presence of allergens. These insights could be used for decision making within food allergen management. Based on the mean values of the simulated profit distributions, this study concludes that both the considered scenarios are economically feasible and show a payback period of around eight months if prices can be increased to match consumers' additional WTP. Internalising all costs without passing them along to consumers would result in losses in both scenarios. As these additional costs could be seen as an investment for improving the image of the catering business (which was not considered here), food services may be able to successfully increase prices, which will allow them to remain in business. In future research, other out of home eating establishments, like hotels and restaurants, could also be considered. If more such establishments serve allergen free food, real market data could be obtained to validate the findings of the present study.

\section{Acknowledgements}

The authors acknowledge the cooperation of Joke van Buuren and Roy Burgman, Sodexo to his study. The study was partly financed by the Ministry of Economic Affairs, the Netherlands. The authors declare to have no conflict of interest.

\section{Supplementary material}

Supplementary material can be found online at http:// dx.doi.org/10.3920/QAS2014.0568.

Table S1. Input values for cost and benefit items considered in the model.

Table S2. Values for fixed cost items considered in the model.

Table S3. Values for variable cost items (costs per month) considered in the model.

\section{References}

Ahuja, R. and Sicherer, S.H., 2007. Foodallergy management from the perspective of restaurant and food establishment personnel. Annals of Allergy, Asthma and Immunology 98: 344-348.

Ajala, A.R., Cruz, A.G., Faria, J.A.F., Walter, E.H.M., Granato, D. and Sant Ana, A.S., 2010. Food allergens: knowledge and practices of food handlers in restaurants. Food Control 21: 1318-1321.

Bailey, S., Albardiaz, R., Frew, A. and Smith, H., 2011. Restaurant staff's knowledge of anaphylaxis and dietary care of people with allergies. Clinical and Experimental Allergy 41: 713-717.

Batt, P. and Noonan, J., 2009. Global trends in food quality: an exploratory study in fresh produce supply chains. ISHS Acta Horticulturae (XVI International Symposium on Horticultural Economics and Management) 831: 95-104.

Breidert, C., Hahsler, M., and Reutterer, T., 2006. A review of methods for measuring willingness-to-pay. Innovative Marketing 2: 8-32.

Day, L., Augustin, M., Batey, I. and Wrigley, C., 2006. Wheat-gluten uses and industry needs. Trends in Food Science and Technology 17: 82-90.

Deibel, K., Trautman, T., DeBoom, T., Sveum, W.H., Dunaif, G., Scott, V.N. and Bernard, D.T., 1997. A comprehensive approach to reducing the risk of allergens in foods. Journal of Food Protection 60: 436-441.

European Commission (EC), 2000. Directive 2000/13/EC of the European Parliament and of the Council of 20 March 2000 on the approximation of the laws of the Member States relating to the labelling, presentation and advertising of foodstuffs. Official Journal of the European Communities L109: 29-42.

European Commission (EC), 2003. Commission Directive 2003/63/EC of 25 June 2003 amending Directive 2001/83/EC of the European Parliament and of the Council on the Community code relating to medicinal products for human use. Official Journal of the European Union L159: 46-94.

European Commission (EC), 2006. Commission Directive 2006/142/EC of 22 December 2006 amending Annex IIIa of Directive 2000/13/EC of the European Parliament and of the Council listing the ingredients which must under all circumstances appear on the labelling of foodstuffs L368: 110-111.

European Commission (EC), 2007. Commission Directive 2007/68/EC of 27 November 2007 amending Annex IIla to Directive 2000/13/EC of the European Parliament and of the Council as regards certain food ingredients. Official Journal of the European Union L310/11-14.

European Commission (EC), 2009. Commission Regulation (EC) No. 41/2009 of 20 January 2009 concerning the composition and labelling of foodstuffs suitable for people intolerant to gluten. Official Journal of the European Union L16: 3-5.

European Commission (EC), 2011. Regulation (EU) No. 1169/2011 of the European Parliament and of the Council of 25 October 2011 on the provision of food information to consumers, amending Regulations (EC) No. 1924/2006 and (EC) No. 1925/2006 of the European Parliament and of the Council, and repealing Commission Directive 87/250/EEC, Council Directive 90/496/EEC, Commission Directive 1999/10/EC, Directive 2000/13/EC of the European Parliament and of the Council, Commission Directives 2002/67/ EC and 2008/5/EC and Commission Regulation (EC) No 608/2004. Official Journal of the European Union L304: 18-63. 
Flabbee, J., Petit, N., Jay, N., Guénard, L., Codreanu, F., Mazeyrat, R. and Moneret-Vautrin, D., 2008. The economic costs of severe anaphylaxis in France: an inquiry carried out by the Allergy Vigilance Network. Allergy 63: 360-365.

Food Safety Authority Ireland, 2012. Overview of changes to food labelling introduced under the new food information regulation. Food Safety Authority Ireland, Dublin, Ireland. Available at: http:// tinyurl.com/ostpo8v.

Gendel, S.M. and Zhu, J., 2013. Analysis of US Food and Drug Administration food allergen recalls after implementation of the Food Allergen Labeling and Consumer Protection Act. Journal of Food Protection 76: 1933-1938.

Gupta, R., Sheikh, A., Strachan, D.P. and Anderson, H.R., 2007. Time trends in allergic disorders in the UK. Thorax 62: 91-96.

Hadley, C., 2006. Food allergies on the rise? Determining the prevalence of food allergies, and how quickly it is increasing, is the first step in tackling the problem. EMBO reports 7: 1080.

Hertzman, J., and Barrash, D., 2007. An assessment of food safety knowledge and practices of catering employees. British Food Journal 109: 562-576.

Jackson, L.S., Al-Taher, F.M., Moorman, M., DeVries, J.W., Tippett, R., Swanson, K.M. and Estes, S., 2008. Cleaning and other control and validation strategies to prevent allergen cross-contact in foodprocessing operations. Journal of Food Protection 71: 445-458.

Johannesson, M., 1997. Some further experimental results on hypothetical versus real willingness to pay. Applied Economics Letters 4: 535-536.

Kronenberg, S.A., 2012. Food allergy risk management: more customers, less liability. Journal of Foodservice Business Research 15: 117-121.

KTBA People in Food, 2013. Verplichte voedselinformatie. KTBA Kwaliteitszorg BV, Kaatsheuvel, the Netherlands. Available at: http://tinyurl.com/oupvaop.

Kumar, S. and Budin, E.M., 2006. Prevention and management of product recalls in the processed food industry: a case study based on an exporter's perspective. Technovation 26: 739-750.

Leitch, I., Walker, M. and Davey, R., 2005. Food allergy: gambling your life on a take-away meal. International Journal of Environmental Health Research 15: 79-87.

Neill, H.R., Cummings, R.G., Ganderton, P.T., Harrison, G.W. and McGuckin, T., 1994. Hypothetical surveys and real economic commitments. Land Economics 70: 145-154.
Nwaru, B., Hickstein, L., Panesar, S., Roberts, G., Muraro, A. and Sheikh, A., 2014. Prevalence of common food allergies in Europe: a systematic review and meta-analysis. Allergy 69: 992-1007.

O'Neil, C.E., Zanovec, M. and Nicklas, T.A., 2011. A review of food allergy and nutritional considerations in the food-allergic adult. American Journal of Lifestyle Medicine 5: 49-62.

Poms, R.E. and Astley, S., 2011. MoniQA: an update of the European funded Network of Excellence in 2011. Quality Assurance and Safety of Crops \& Foods 3: 89-101.

Pratten, J.D. and Towers, N., 2003. Food allergies: a problem for the catering industry. British Food Journal 105: 279-287.

Remington, B.C., Baumert, J.L., Marx, D.B. and Taylor, S.L., 2013. Quantitative risk assessment of foods containing peanut advisory labeling. Food and Chemical Toxicology 62: 179-187.

Sicherer, S.H., Muñoz-Furlong, A. and Sampson, H.A., 2003. Prevalence of peanut and tree nut allergy in the United States determined by means of a random digit dial telephone survey: a 5-year follow-up study. Journal of Allergy and Clinical Immunology 112: 1203-1207.

Taylor, S., Hefle, S., Bindslev-Jensen, C., Atkins, F., Andre, C., Bruijnzeel-Koomen, C. and Eigenmann, P., 2004. A consensus protocol for the determination of the threshold doses for allergenic foods: how much is too much? Clinical \& Experimental Allergy 34: 689-695.

Trogdon, J.G., Ekwueme, D.U., Subramanian, S. and Crouse, W., 2013. Economies of scale in federally-funded state-organized public health programs: results from the National Breast and Cervical Cancer Early Detection Programs. Health Care Management Science 17: 321-330.

Van Putten, M., Frewer, L., Gilissen, L., Bart, G., Peijnenburg, A. and Wichers, H., 2010. Stakeholder and consumer views regarding novel hypoallergenic foods. British Food Journal 112: 949-961.

Versluis, A., 2012. Unexpected allergic reactions to food in adult patients with peanut or hazelnut allergy: an explorative study. MSc thesis, Faculty of Medicine, University of Utrecht, Utrecht, the Netherlands.

Voedingscentrum, 2013. Allergenen en de nieuwe Europese wet Voedselinformatie. Stichting Voedingscentrum Nederland, Den Haag, the Netherlands. Available at: http://www.voedingscentrum.nl.

Watson, R., 2013. Managing allergens from a food retailer perspective including an update on allergen labelling regulation. Nutrition Bulletin 38: 405-409. 